\title{
A Comparison of the Effects of Frequency and Intensity of Anaerobic Exercises on Some Physical Fitness Factors in Martial arts Athletes
}

\author{
Babak Barkadehi \\ Department of Physical Education, Rasht Branch, Islamic Azad University, Rasht, Iran \\ Corresponding Author Email: Ell1357@yahoo.com \\ Mohamadreza Abedimahzoun \\ Faculty of Management and Accounting, Islamic Azad University (IAU), Qazvin, Iran
}

Doi:10.5901/mjss.2014.v5n23p2667

\begin{abstract}
The present paper compares the effects of frequency and intensity of anaerobic exercises on legs explosive power and aerobic power of martial arts sportsmen. 45 martial arts sportsmen (aged 16-+ 1.93 on average and height average equal to 167-+0.09 centimeters and weighed 57.43+- 11.25 kilograms) were selected by questionnaire (from among 120 people) and were put into three 15-member groups (two exercise groups and one control group). Pretest and final test measurements involved legs explosive power and aerobic power. Respondents exercised 8 weeks in two exercise groups, one group took part in two session highly intense exercises and the other group took part in three-session moderate exercises. The control group did not have any regular and planned exercises during the eight weeks. The exercises included Plyometric, speed running and acceleration running which were conducted in different intensities in the two groups. These alternative exercises lasted 75 minutes in each session. The three-session group did moderately-intense exercises and the two-session group conducted highly-intense exercises and ANOVA analysis showed that changes in explosive power and aerobic power had significant differences in the two groups in comparison with the control group $(p<=0.05)$. However, there was no difference between the average and highly-intense exercise groups in the changes of the variables $(p<=0.05)$. Results showed that highly-intense twosession exercises and moderately-intense three-session exercises had almost similar effects in many physical education factors like aerobic and anaerobic power.
\end{abstract}

Keywords: anaerobic exercises, aerobic exercises, anaerobic power.

\section{Introduction}

Success in any sport requires special physiologic and physical capabilities. Physical fitness has an effective role in sports performance. Knowledge about sportsmen physical fitness is one of the main methods of determination of effectiveness of exercise programs on sports performance. Continuous measurement of physical capabilities is one of the main duties of sports coaches. Therefore, taking tests is the first step in selection of sportsmen and this is followed by facilitated exercises control and formulation (1). Anaerobic power which is one of the elements of physical fitness is importantbio motion ability in sports which need short-term and rapid efficient activities (2). Evaluation of anaerobic power in athletes and especially sports which involve quick and explosive movements is very important (3). Within the past two decades, athletes have become more powerful and sport activities performances especially anaerobic performances have been improved (4). Any exercise has some principles and these involve manipulation of some variables in training program of athletes like exercises types, order of movements and activities, intensity of activities (frequency and intensity), relaxation in intervals, activities and the number of exercise sessions. These principles are used because stimulation and recovery intervals provide effective compatibilities $(5,6$, and 7$)$. In martial arts, various factors like power, speed, flexibility, agility, balance, positional stamina and rhythm and muscular-nervous harmony are important. Martial arts athletes must exercise for years to improve their techniques and develop necessary speed and power for fulfilling their potential. Basically, any sport requires specific types of physical fitness (8). From biological viewpoint, a sport feature can be observed in speed and energy consumption level in every muscle. For instance, endurance sports activities require aerobic system resources and power sports activities require anaerobic system energy (5). Martial arts require involvement of all energy systems and recognition of appropriate training methods for improvement of efficiency is very complex and needs repetitive measurements and analyses. Although it seems that dominating energy system in martial arts is anaerobic 
system including fosfagenenergy system and glycolysis, aerobic energy systems also seems to have a determining role in martial arts $(5,9)$.

One important issue for martial arts coaches and athletes is that how many sessions of exercise can influence best on athletes'fitness. Another issue is that how physical fitness factorschange if we manipulate the number of exercise sessions and intensity of exercises. Results of studies showed that compound exercises (anaerobic and aerobic) can increase anaerobic and aerobic power significantly $(10,11)$. Of course, many references and reports mention three sessions of exercise per week for reaching appropriate level of fitness (12). Some studies revealed that select combined exercises (exercises focused on improvement of physical fitness, body mass index and fat percentage) have increased aerobic power significantly but did not have any influence on anaerobic exercises (5). On the other hand, reduction in the number of sessions and increase in intensity of aerobic exercises in non-athlete girls' training program reduced aerobic power and increased anaerobic power significantly (13). In most studies, several factors have been investigated in exercises which are done a number of specific sessions. In these studies, either frequency or intensity of exercises was constant and impacts of one variable on other variables were analyzed and there are few studies which use both intensity and frequency variables as independent variables. An investigation of the previous studies reveals that there are some disagreements concerning impacts of frequency and intensity of exercises on physical fitness dimensions. Therefore, the present research was designed for clarifying this issue. Intensity and frequency of training sessions are manipulated in this research in order to find the impact of this manipulation on some physical fitness factors and athletes physiological variables in martial arts athletes. Moreover, exercises in this research mainly emphasize on anaerobic training (Plyometric and power and speed) and are on alternative sessions, which did not receive much attention in the previous related studies (5).

\section{Research Methodology}

Statistical population of the present research included male martial arts athletes (aged 16-19) in Guilan Province, Iran. 45 athletes were selected using questionnaire (including general information, sports and medical background and ...) and via accessible purposeful sampling method (from among 120 athletes). Then, they were put into three groups and were investigated for 8 weeks.

\section{Data Collection}

In this research, pretest and final test were conducted similarly. Sergeant test was used for evaluation of anaerobic power (legs explosive power)(Lewis's Nomogramfor evaluation of power via difference between jumping distance and body weight) and step test by means of Mac Ardelmethod (three minute step test) was used for evaluation of aerobic power. In this method, an athlete first puts his or her right foot on stairs and then puts his or her left foot when going upstairs. Then, while coming downstairs, he or she puts his or her right foot on stairs and then puts his or her left foot and continues accordingly. The athlete must take 26 steps in a minute. Immediately after test ended, the athlete sits and after 5 seconds, the number of heartbeats is counted in one minute and $\mathrm{VO}_{2 \max }$ is calculated based on the following formula. $\mathrm{VO}_{2 \max }=111.33$-[heartbeat $\left.{ }^{\star} 0.421\right]$

\section{Research Implementation Method}

After putting respondents in three groups, all respondents received a pretest and then the groups received alternative exercise programs with specific intensities.

1. the group with two exercise sessions per week took part in a highly-intense anaerobic program (80-90\% of maximum heartbeat). This group received exercises for 8 weeks and two sessions per week.

2. the group with three sessions of exercise per week took part in a moderately-intense anaerobic program (70$80 \%$ of maximum heartbeat). This group received exercises for 8 weeks and three sessions per week.

3. the control group did not have any regular exercises but took part in the primary and final tests.

Each exercise session (lasting 75 minutes) included three stages: 1. Warm-up (15 minutes), 2. Main exercises (50 minutes), 3. cooling (10 minutes). Only intensity of main exercises was different in the two exercise groups. The main exercise involved specific skills regarding plyometric program, power and speed skills. Plyometric exercises like hopscotch, jumps, leaps and speed exercises like speed and accelerated running. 


\section{Statistical Data Analysis}

Data were analyzed in descriptive and inferential levels. Kolmogrov-Smearnov test was used to investigate the normality of data. after making sure of the normality of data distribution, parametric statistical methods were used for inferential analysis. These methods included correlated $t$ test for intra-group changes and one-way variance (ANOVA) for investigation of inter-group changes. Tuki's test was used for investigation of place and direction of changes and SPSS software (version 16) was sued for doing statistical operation.

\section{Research Findings}

45 athletes out of 120 respondents who took part in survey managed to end training period and their particulars are summarized in table 1.

Table 1. Mean and standard deviation of respondents' physical characteristics

\begin{tabular}{|c|c|c|c|}
\hline $\begin{array}{c}\text { Control group } \\
(15 \text { people })\end{array}$ & $\begin{array}{c}\text { Two-session moderately-intense } \\
(15 \text { people })\end{array}$ & $\begin{array}{c}\text { Two-session highly-intense } \\
(15 \text { people })\end{array}$ & \multicolumn{2}{|c|}{ Group } \\
\hline $1.18 \pm 17$ & $2.06 \pm 16$ & $2.3 \pm 17$ & Age (years) \\
\hline $0.09 \pm 168$ & $0.09 \pm 165$ & $0.09 \pm 168$ & Height (cm) \\
\hline $10.18 \pm 56.91$ & $13.45 \pm 55.16$ & $9.96 \pm 60.23$ & Weight $(\mathrm{kg})$ \\
\hline
\end{tabular}

Considering table 2 and the results of ANOVA test, the difference between the groups in legs explosive power and aerobic power $\left(\mathrm{VO}_{2 \max }\right)$ is significant.

Table 2. Analysis of difference between dependent variables in pretest and posttest in the three groups

\begin{tabular}{|c|c|c|c|c|c|c|}
\hline Dependent variables & Table of variance analysis & Sum of squares & $\mathrm{df}$ & Square mean & F value & Sig. \\
\hline \multirow{3}{*}{ Explosive leg power (watts) } & Inter-group & 63075.244 & 2 & 31537.622 & \multirow{3}{*}{8.397} & \multirow{3}{*}{${ }^{*} 0.001$} \\
\hline & Intra-group & 157745.333 & 42 & 3755.841 & & \\
\hline & Total & 220820.578 & 44 & …............. & & \\
\hline \multirow{3}{*}{$\begin{array}{l}\mathrm{Vo}_{2 \max } \\
(\mathrm{ml} / \mathrm{kg} / \mathrm{min})\end{array}$} & Inter-group & 1464.563 & 2 & 732.281 & \multirow{3}{*}{9.379} & \multirow{3}{*}{${ }^{*} 0.000$} \\
\hline & Intra-group & 3279.132 & 42 & 78.075 & & \\
\hline & Total & 4743.697 & 44 & …......... & & \\
\hline
\end{tabular}

Significance in $p<=0.05$

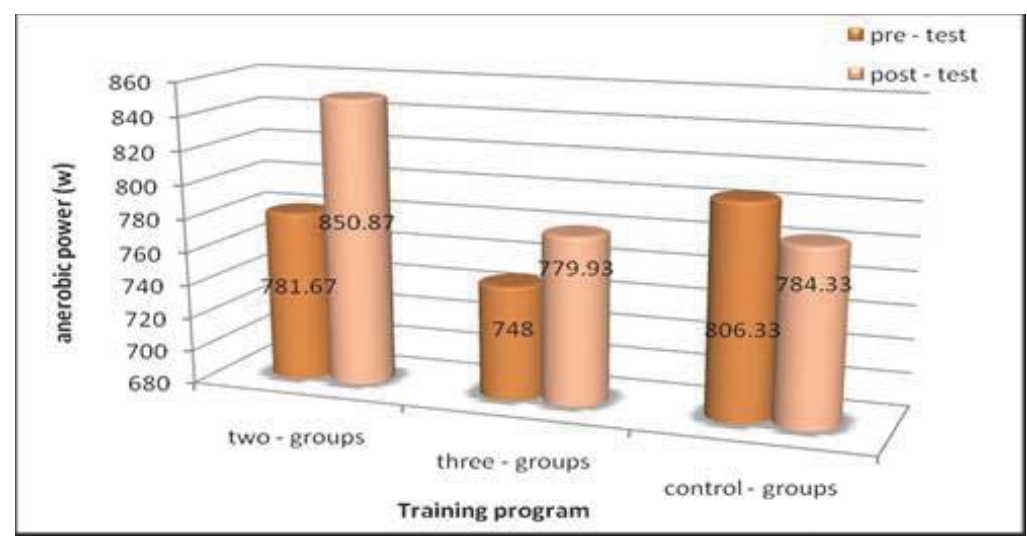

* difference between before and after training period in that group $(p<=0.05)$.

Figure 1. anaerobic power in the three groups before an after training period

According to figure 1, anaerobic power increased significantly in both groups from pretest to final test $(p<=0.05)$. in the control group, a significant reduction was observed in respondents' anaerobic power before and after exercise period 
$(p<=0.05)$. as it can be seen, anaerobic power improvement was best for the two-session group but it did not have any significant difference with the three-session group.

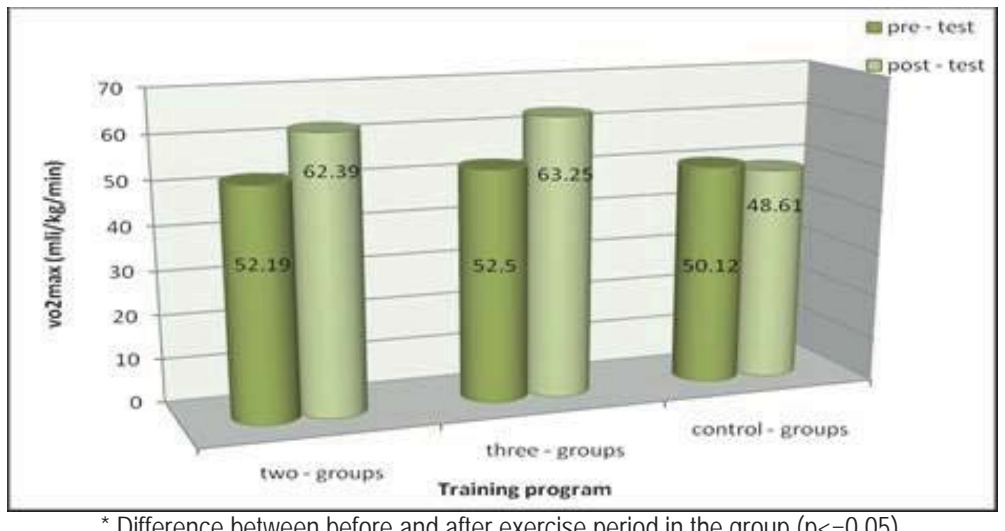

* Difference between before and after exercise period in the group $(p<=0.05)$.

Figure 2. Aerobic power in the three groups before and after exercise period

According to figure 2, aerobic power increased significantly in both exercise groups $(p<=0.05)$. However, the control group did not show any significant change in aerobic power before and after exercise period $(p<0.05)$.

Table 3. Difference level in dependent variables of the groups using Tuki's test

\begin{tabular}{||c|c|c|c||}
\hline \hline \multicolumn{2}{|c|}{ Multiple comparisons } & \multicolumn{2}{c||}{ Significance level of dependent variables } \\
\hline Empirical group A & Empirical groups B & Anaerobic power & Aerobic power \\
\hline \hline \multirow{2}{*}{ Two-session } & Three-session & 0.23 & 0.970 \\
\cline { 2 - 4 } & control & ${ }^{*} 0.001$ & ${ }^{*} 0.002$ \\
\hline \hline \multirow{3}{*}{ Three-session } & Two-session & 0.230 & 0.970 \\
\cline { 2 - 4 } & control & 0.052 & ${ }^{*} 0.001$ \\
\hline \hline \multirow{2}{*}{ control } & \multirow{2}{*}{0.002} \\
\cline { 2 - 4 } & Two-session & $*^{*} 0.001$ & ${ }^{*} 0.001$ \\
\hline
\end{tabular}

* significant inter-group changes difference in $(p<=0.05)$ level.

Considering the results of Tuki's test for comparison of inter-group changes in anaerobic power, there is no significant difference between two-session group and three-session group. Further, there is no significant difference between anaerobic power of the three-session group and control group. However, there is a significant difference between twosession highly-intense group and control group $(p<=0.05)$. considering the results of this test for comparison of aerobic power changes, table 3 shows that there is no significant difference between the two-session and three-session groups in aerobic power. However, there is significant differences between two-session group and control group and also threesession group and control group ( $p<=0.05)$.

\section{Conclusion and Discussion}

According to the results of the research, both exercise programs with different intensities resulted in significant increase in anaerobic power. However, results of statistical analyses revealed that difference between exercise groups in this variable is not significant. This conforms to the results of studies $(10,12,13,14,15,16)$. While mean of anaerobic power growth in the two-session highly-intense program was better than the three-session moderately-intense exercise group, the difference was not significant. Therefore, it can be said that exercise programs with different intensities and frequencies did not have any significant impact difference on anaerobic power of athletes $(p<=0.05)$. however, there was a significant difference between impacts of two-session group exercises and the control group $(p=0.001)$. 
The main conclusion on the changes in this variable is that three-session moderately intense exercises and highlyintense two-session exercises can improve leg muscles and their effects are the same. Of course, in comparison with the control group, results of the two-session program showed a significant difference and this can indicate the importance of intensity of exercise.

This is while Debidi et al showed that legs anaerobic power increased significantly in an investigation of the impacts of a 90-minute exercise session in a week (14). Foturez investigated the impact of 12 weeks of plyometric exercise for three sessions per week on vertical jumping of 31 men. Results revealed an increase in legs power (anaerobic power). (17). Sharp et al studied the impact of 8 weeks of training (five sessions per week, each session lasting 90 minutes) with Ergometer Bikes on anaerobic compatibilities of 10 male students. After 6 weeks of exercise, respondents' performance increased from 564 watts to 657 watts significantly (18). Mechanism of improvement of legs anaerobic power can be related to the types of exercises.

Results showed that both exercise programs increased aerobic power significantly while control group showed a significant reduction. The reduction of aerobic power in this group can be attributed to lack of regular exercise. However, analyses showed that difference between the two exercise groups in this variable is not significant and this conforms to the results of the following studies $(10,12,13,19,20,21$, and 22). While mean value of aerobic power increase in threesession group was higher than that of the two-session group, the difference was not significant. In other words, impacts of exercise programs with different intensities and frequencies on aerobic power of athletes did not have any difference $(p<=0.05)$. however, there was significantdifference between the three-session group and two-session group and control group in this variable $(p<0.05)$.

Rob Dofield studied the impact of highly-intense exercise on increase in $\mathrm{VO}_{2 m a x}$. in his research, 10 women did alternative exercises with $75 \%$ of maximum heartbeat intensity (2 minutes of work and 1 minute rest). Duration of exercises was 8 weeks and 3 days per week. After final test, $\mathrm{VO}_{2 \max }$ increased by 2.78-+ 0.3 (22). In fact, this result conforms to some other studies results. In his research, significant effects were observed both in groups and between groups from pretest to posttest. Results showed that three moderate exercise session per week and two highly-intense exercise sessions per week increases maximum oxygen significantly and their impacts are not different. it seems that moderate exercises tend to have better impacts. The exercises in this research were plyometric and acceleration and mechanisms involved in exercises were not related to body aerobic power and maximum oxygen used. Therefore, the cause for improvement is something else. For instance, reduction in under-skin fat and increase in fatless weight can be an important factor in increasing aerobic power.

\section{References}

Qaderi, MahBanou. (2002). "relationship between body fat percentage, body fat distribution and physical activities and dangerous cardiovascular diseases factors in middle-aged women", Master degree thesis, Guilan University.

Rajabi, Hamid et al, (2001), "basic concepts in aerobic fitness", National Olymic Committee Press, first printing, Tehran-winter.

Baumgartner, T. Jackson, A. (1991). Measurment for evaluation in physical education and exercise science WBc. Pub.

James, D V. DOUST, JH. (1998). Oxygen uptake during moderate intensity: response following a single bout of interval training, Eur. J. Appl, physiolOccupphysiol med; 77 (3): $551-5$.

Wilford, Henry et al. (1991). "sportsexercises for women", translated by Mohsen Bolouriyan, Journal of sports and value, published by organization of Physical Education, vol. 1. Numbers 103 and 309.

Fox .E ,et al. (1975). frequency and duration of interval training programs and changes in aerobic power.

Lamarch B, Despres J. P., Poulit M. C. and Bouchard, C. (1992). Is body loss a determinate factor in the improvement of carbohydrate and lipid metabolism following aerobic exercise training in obese woman? Metabolism; 71 (77): 1249 - 56.

Daneshmandi, Hamzeh, (2000), "influence of power exercises of power, speed and agility in wheel-chair basketball players". Sports medicine, number 4. 39-54.

William P. Ebben, MS. Watts, PB. (1998)."A review of combined weight training and plyometric training modes: complex training". strength and conditioning.

Agha Malek, SHabKhiz. Qojeli. (2001). " a comparison of compound and aerobic physical activities on increase in physical fitness level in Tehran University students". Journal of movement. Number 8: 93-102.

Hoseinpour, Sadigheh. Souri, Rahman. Bahrami, SHahab. (2001). " a comparison of effectiveness of two exercise programs on muscular-skeleton and cardiovascular indicators in sedentarygirls". Journal of sports biosciences. Number 2: 80-85.

Aryanfar, Hamid Reza. (2002). "investigation of the impact of a select exercise program on some physical fitness and physiologic factors in students aged 15-18 in Arak City". Master degree thesis. Arak University.

Omidi, Mahnaz. Rajabi, Hamid. Balouchi, Bahram. (2010). "investigation of the impact of reduction in frequency of sessions and increase in intensity of exercise on body build, aerobic and anaerobic power of non-athlete female students": sports biosciences; number 6: 21-39. 
DebidiRoshan, Vali Allah. (1999). "investigation of the impact of select exercises in physical education course on some structural and physiological features of non-athlete studnts". Master degree thesis, Tehran University.

Samavat, Tahereh. HojjatZadeh, Elliyeh. (1995), "booklet of center for management of diseases-heart diseases prevention unit".

Roberts, John. (1976). "Effect of frequency and intensity of training". research quarterly; 47: 1.

Fax, Mattews. (1996). "sports physiology": translated by AsgharKhaledan, first printing, volume 1-Tehran: Tehran University Press.

Sharp, RL. Et.al. (1989). Medicine sport exercise.

Hodgetts ,V. Coppack, SW. Frayn, KN. and Hockaday,TD.(1991). factorscontorolling fat mobilization from human subcutaneous adipose tissue during exercise. J ApplPhysiol; 71(2): 445.

Kraemer WJ. Mazzetti SA. Nindl BC. Gotshalk LA. Volek JS. Bush JA. Et al. (2001). "effect of resistance training on women's strength/ power and occupational performances". Med Sci Sports Exerc; 33: 1011-25.

Morris, PMV. (1978). " the karate - do manual". Vol 1.

Duffield, R. Edge, J. and Bishop, D. (2006). "effects of high intensity interval training on the $\mathrm{VO}_{2}$ response during severe exercise". School of Human Movement and Exercise Science, the University of Western Australia, 35 stirling highway, Crawley, Wa 6009, Australia. 